\title{
Apolipoprotein E $\varepsilon 4$ allele is a risk factor for familial and sporadic presenile Alzheimer's disease in both homozygote and heterozygote carriers
}

David St Clair, Morag Rennie, Euan Slorach, Jennie Norrman, Celia Yates, Andrew Carothers

\begin{abstract}
While apoliprotein $\mathrm{E}$ (ApoE) 84 allele is now a well established risk factor for familial and sporadic senile Alzheimer's disease (AD), its role in the development of the rarer presenile or early onset type is controversial. Early studies showed no association; later ones found enrichment for the $\varepsilon 4$ allele in familial or sporadic types or both. We have ApoE genotyped a series of Scottish people $(n=85)$ with early onset AD. We find highly significant enrichment for both homozygote and heterozygote ApoE $\& 4$ allele carriers in familial and sporadic early onset $A D$ with a pattern closely resembling that in late onset $A D$.
\end{abstract}

(f Med Genet 1995;32:642-644)

$\mathrm{AD}$ is a neurodegenerative disorder characterised by $\beta$ amyloid peptide deposits in senile plaques and cerebral blood vessel walls, and neurofibrillary tangles (NFTs) within neurones of the cerebral cortex and hippocampus. ApoE has been found localised to senile plaques, vascular amyloid, and NFTs ${ }^{12}$ and one allele, $\varepsilon 4$, is significantly associated with familial and sporadic late onset $\mathrm{AD} .^{2-8} \mathrm{ApoE}$ is a $34 \mathrm{kDa}$ protein that is involved in cholesterol and triglyceride transport, mediating their clearance from plasma by interaction with low density lipoprotein receptor. ${ }^{9}$ Unlike other lipoproteins which are mainly synthesised in the liver, ApoE is also synthesised in astrocytes and oligodendrocytes in the central nervous system. ${ }^{9}$ It has three isoforms corresponding to alleles $\varepsilon 2, \varepsilon 3$, and $\varepsilon 4$. The isoform corresponding to $\varepsilon 4$ shows high avidity binding to $\beta$ amyloid peptide ${ }^{2}$ and it is suggested that this accelerates $\beta$ amyloid deposition and so the development of $A D .{ }^{10}$ Although numerous studies have now shown an association between the ApoE $\varepsilon 4$ allele and both familial and sporadic late onset $\mathrm{AD},{ }^{2-8}$ the relationship with presenile/early onset $\mathrm{AD}$ ( $<65$ years) is still controversial. Initial studies failed to find a significant association between the ApoE $\varepsilon 4$ allele and the risk of familial early onset $\mathrm{AD} \cdot{ }^{11-13}$ However, most data in these early studies came from $\mathrm{AD}$ families with a mutation in the amyloid precursor protein (APP) gene or linked to a locus on chromosome 14 . When, in later reports, patients were examined who did not have
APP mutations and, based on age of onset, were less likely to be chromosome 14 linked cases,${ }^{14-16}$ positive associations with the ApoE $\varepsilon 4$ allele were observed. This suggests that genetic heterogeneity among early onset $\mathrm{AD}$ must be taken into account when interpreting ApoE associations. Chartier Harlin et $a l^{14}$ found the $\varepsilon 4$ allele significantly raised in 34 sporadic early onset English $\mathrm{AD}$ cases, and Okuizumi et $a l^{15}$ found similar findings in 44 sporadic early onset Japanese cases. The largest study of early onset $\mathrm{AD}$ to date, based on a population in the northern Dutch provinces and Rotterdam, ${ }^{16}$ gave an overall frequency for the $\varepsilon 4$ allele in early onset $\mathrm{AD}$ of $35 \%$. When patients were subdivided by family history (positive $\mathrm{n}=$ 107 and negative $n=68$ ) the $\varepsilon 4$ allele was 1.6 times higher in the family history positive group (41\%) compared to the family history negative group (25\%). Further analysis showed that an increased risk of early onset $\mathrm{AD}$ exists for $\varepsilon 4$ homozygote carriers regardless of family history of dementia, but increased risk of early onset $\mathrm{AD}$ for ApoE $\varepsilon 4$ heterozygote carriers could only be shown in subjects with a positive family history. This suggested that while a single $\varepsilon 4$ allele increases the risk of late onset $\mathrm{AD}$, alone it is insufficient to increase the risk of onset of illness before the age of 65 years. ${ }^{17}$ In order to address these questions further we have ApoE genotyped a cohort of serially collected Scottish cases with a definite or probable diagnosis of early onset $\mathrm{AD}$ and compared ApoE $\varepsilon 4$ allele frequency in familial and sporadic cases with non-demented control groups.

\section{Methods}

PATIENT AND NORMAL DNA SAMPLES

Early onset $A D(n=85)$

All met NINCDS criteria for definite $(n=19)$ or probable $\mathrm{AD}(\mathrm{n}=66) .{ }^{17}$ Definite cases died in either psychiatric or geriatric wards and had moderate or numerous plaques and tangles in frontal and temporal cortex and hippocampus. Cases were collected by the MRC Brain Metabolism Unit between 1979 and 1988. Probable cases were identified in hospital wards or referred by clinical colleagues throughout the central belt of Scotland. Age of onset averaged 57 years (SD 6), (28 M, $57 \mathrm{~F})$. Age at onset was defined as the age at which memory loss or change in behaviour was first noticed. All cases were screened for mutations of the amy- 
Table 1 Frequencies of $\varepsilon 2, \varepsilon 3$, and $\varepsilon 4$ apolipoprotein $E$ alleles in early onset $A D$, late onset $A D$, and nondemented control groups

\begin{tabular}{llll}
\hline & \multicolumn{3}{l}{ Allele frequencies } \\
\cline { 2 - 4 } & $\varepsilon 2$ & $\varepsilon 3$ & $\varepsilon 4$ \\
\hline $\begin{array}{l}\text { Early onset } \mathrm{AD} \\
(\mathrm{n}=85)\end{array}$ & 0.06 & 0.53 & 0.41 \\
$\begin{array}{l}\text { Late onset } \mathrm{AD} \\
(\mathrm{n}=68)\end{array}$ & 0.01 & 0.60 & 0.38 \\
$\begin{array}{l}\text { Non-demented controls } \\
(\mathrm{n}=47)\end{array}$ & 0.03 & 0.84 & 0.13 \\
$\begin{array}{l}\text { Scottish population } \\
(\mathrm{n}=400)\end{array}$ & 0.08 & 0.77 & 0.15 \\
\hline
\end{tabular}

Highly significant $(\mathrm{p}<0.001)$ differences between $\varepsilon 4$ frequency in early onset $\mathrm{AD}$ and both control groups. No significant in early onset $\mathrm{AD}$ and both control groups. No significant

loid precursor protein gene. None was found..$^{18}$ A systematic enquiry concerning a family history of dementia was made in all cases through spouses and first degree relatives and hospital case notes. Fourteen cases were defined as familial, where there was evidence of early onset $\mathrm{AD}$ in a first degree relative. Either clinical symptoms began before 65 or the patient required long term care before 70 years. Seventyone cases were defined as sporadic early onset $\mathrm{AD}$; either no $\mathrm{AD}$ or only late onset $\mathrm{AD}$ was identified in first degree relatives after systematic enquiry.

Late onset $A D(n=68)$

The mean age of death was 81 (range 69-91) (19 M, $49 \mathrm{~F}$ ). All died in hospital and had clinical and neuropathological features to satisfy NINCDS criteria for diagnosis of definite AD. ${ }^{18}$

Aged, non-demented controls $(n=47)$

The mean age of death was 78 (range 67-91) (29 M, $18 \mathrm{~F})$. All had a full neuropathological examination and showed no features of $\mathrm{AD}$.

Population data were also available for ApoE allele frequencies in Scotland $^{19}(n=400)$. Mean age was 53 (SD 0.22). ApoE allele frequencies in the last three groups have already been described. ${ }^{1920}$
ApoE $\varepsilon 4$ allele status was determined on genomic DNA samples from the first three groups by polymerase chain reaction (PCR) amplification of ApoE gene sequences followed by restriction isotyping. The method used was essentially that described by Wenham et $a l^{21}$ with the exception that $6 \%$ metaphor agarose gels were used for product visualisation.

\section{Results}

Table 1 gives the ApoE allele frequencies for each of the four groups. Highly significant $(p<0.001)$ differences were observed in ApoE $\varepsilon 4$ allele frequency in both early and late onset $\mathrm{AD}$ when compared to non-demented control groups. By contrast, no significant differences were detectable between the dementia groups themselves or between the two control groups. There was also no correlation within either group of ApoE $\varepsilon 4$ status with age of onset of AD.

Table 2 gives ApoE $\varepsilon 4$ allele numbers and percentages in early onset $\mathrm{AD}$ and control groups, as well as separate figures for family history positive and negative cases. Highly significant $(p<0.001)$ differences in $\varepsilon 4$ allele numbers were found when the early onset $\mathrm{AD}$ group as a whole was compared to the non-demented controls or the Scottish population $\left(\chi^{2}=21.6\right.$ and $72 \cdot 3$ respectively, $2 \mathrm{df}$ ). These differences remained highly significant when we analysed separately the family history positive $\left(\chi^{2}=13 \cdot 1\right.$, and $39 \cdot 4,2 \mathrm{df}$ ) and family history negative cases subgroups $\left(\chi^{2}=19 \cdot 1\right.$ and $\left.63 \cdot 1,2 \mathrm{df}\right)$.

Table 3 gives the ODDs ratios for early onset $\mathrm{AD}$ associated with the ApoE $\varepsilon 4$ allele. The genotype frequencies of controls are estimated from population allele frequencies under Hardy-Weinberg assumptions. The risk of early onset $\mathrm{AD}$ is 4.6 times higher for carriers of at least one ApoE $\varepsilon 4$ allele compared to subjects without an ApoE $\varepsilon 4$ allele. The greatest increase is in those with a family history, but does not differ significantly from those without a family history. It is also increased more than four-fold in homozygous 84 carriers compared to heterozygous carriers.

Table 2 Apolipoprotein $E \& 4$ alleles in early onset $A D$

\begin{tabular}{|c|c|c|c|c|c|}
\hline \multirow[t]{2}{*}{ ApoE $\varepsilon 4$ allele } & \multirow{2}{*}{$\begin{array}{l}\text { All early onset } A D \\
(n=85)\end{array}$} & \multicolumn{2}{|l|}{ Family history } & \multicolumn{2}{|l|}{ Controls } \\
\hline & & $+v e(n=14)$ & $-v e(n=71)$ & Non-demented $(n=47)$ & Population $(n=400)$ \\
\hline \multirow{2}{*}{$\begin{array}{l}\text { Frequency } \\
\text { Copy number } \\
2 \\
1 \\
0\end{array}$} & $0 \cdot 41$ & 0.46 & 0.40 & $0 \cdot 13$ & $0 \cdot 15$ \\
\hline & $\begin{array}{l}15(17 \cdot 6 \%) \\
40(47 \%) \\
30(35 \cdot 2 \%)\end{array}$ & $\begin{array}{l}3(21 \%) \\
7(50 \%) \\
4(28 \%)\end{array}$ & $\begin{array}{l}12(17 \%) \\
33(47 \%) \\
26(37 \%)\end{array}$ & $\begin{array}{c}1(2 \%) \\
10(22 \%) \\
36(76 \%)\end{array}$ & $\begin{array}{c}4(1 \%) \\
110(27 \%) \\
286(71 \%)\end{array}$ \\
\hline
\end{tabular}

Table 3 Odd ratios for early onset associated with the ApoE $\varepsilon 4$ allele

\begin{tabular}{lrrr}
\hline $\begin{array}{l}\text { Number of ApoE } \varepsilon 4 \text { alleles } \\
(O \text { is reference) }\end{array}$ & All & $\begin{array}{l}\text { Positive } \\
\text { family history }\end{array}$ & $\begin{array}{l}\text { Negative } \\
\text { family history }\end{array}$ \\
\hline 1 or 2 & $4 \cdot 88(2 \cdot 96 ; 8 \cdot 02)$ & $6 \cdot 65(2 \cdot 00 ; 22 \cdot 1)$ & $4 \cdot 60(2 \cdot 70 ; 7 \cdot 85)$ \\
1 & $3 \cdot 85(2 \cdot 29 ; 6 \cdot 48)$ & $5 \cdot 06(1 \cdot 42 ; 18 \cdot 0)$ & $3 \cdot 67(2 \cdot 10 ; 6 \cdot 41)$ \\
2 & $16.7(7 \cdot 99 ; 35 \cdot 0)$ & $25 \cdot 1(5 \cdot 19 ; 120 \cdot 9)$ & $15 \cdot 4(6 \cdot 97 ; 34 \cdot 1)$ \\
\hline
\end{tabular}

Reference is genotype frequencies estimated from population controls under Hardy-Weinberg assumption. ()$=95 \%$ confidence limits.

Odds ratio $=\frac{\text { Prob (affected/carrier [family history] ) }}{\text { Prob (affected/non-carrier [family history]) }}$

Figures in columns 3 and 4 require the assumption that genotype frequencies in the general population do not depend on the family history. 


\section{Discussion}

Our study shows an increased risk of early onset $\mathrm{AD}$ in ApoE $\varepsilon 4$ allele carriers. The $\varepsilon 4$ allele frequency was at least 2.5 times greater in the early onset $\mathrm{AD}$ group than in both nondemented control samples irrespective of family history, and the increase was highly statistically significant. The increased risk of early onset $\mathrm{AD}$ was greatest in $\varepsilon 4$ homozygotes (16 times) but was also substantial in heterozygotes (3.7 times) compared to non- $\varepsilon 4$ carriers. The differences between family positive and family negative cases were not statistically significant. Our results agree, therefore, with Van Duijn et $a l^{16}$ in showing raised $\varepsilon 4$ allele frequency in familial early onset $\mathrm{AD}$ and with Chartier Harlin $e t a l^{14}$ and Okuizumi et $a l^{15}$ in showing a raised $\varepsilon 4$ frequency in sporadic cases. We differ from Van Duijn et $a l^{16}$ in finding a significant $(p<0.001)$ increase in sporadic cases of $\varepsilon 4$ heterozygotes as well as homozygotes.

The reasons why earlier studies failed to show ApoE $\varepsilon 4$ allele increase in early onset $\mathrm{AD}$ have already been discussed. They were often based on small numbers and may have lacked statistical power, but more important was selection bias. Cases examined were mostly derived from rare families with mutations of the APP gene or linked to chromosome 14. They might be expected to differ in terms of genetic risk factors from the commoner early onset cases present in the general population. Indeed when such latter cases are examined, as in the Dutch and our series, the results are remarkably similar. The only differences in the ApoE $\varepsilon 4$ allele frequencies are in the sporadic cases where, in contrast to the Dutch series, $\varepsilon 4$ heterozygote carriers were significantly increased. This discrepancy may be because of population differences. Also the inclusion criteria for familiality differ between the two studies. The Dutch group included as familial all cases where a first degree relative had $\mathrm{AD}$, irrespective of age of onset. In our series we classified as familial cases only those with a first degree relative with early onset $\mathrm{AD}$ (see above). The two sets of findings are therefore not directly comparable.

The main implication of our data is that the ApoE $\varepsilon 4$ allele is a risk factor for early onset $\mathrm{AD}$. While the risk is greatest in homozygotes it is also raised in $\varepsilon 4$ heterozygotes. It is a risk factor in familial and sporadic cases. The findings are similar to those observed in late onset $\mathrm{AD}$. This means that the relative risk does not change, that is, if $\mathrm{AD}$ occurs in $\varepsilon 4$ carriers it is as likely to be the commoner late onset $\mathrm{AD}$ as in non- $\varepsilon 4$ carriers. However, our findings again raise the issue as to whether from a clinicoepidemiological point of view the two should not be considered as a single population. Finally, the study highlights the risk in extending to early onset $\mathrm{AD}$ as a whole observations made on rare subgroups of autosomal dominant families where findings may be locus specific.

We thank Alec Gordon for neuropathological assessments, Drs Moffoot and Sharpe for access to patient material, and D Brookes for technical advice. David St Clair is supported by the Wellcome Trust.

1 Namba Y, Tomonaga M, Kawasaki $\mathrm{H}$, Otomo E, Ikeda $\mathrm{K}$ Apolipoprotein $\mathrm{E}$ immunoreactivity in cerebral amyloid Apolipoprotein E imm, and kuru plaque amyloid in Creutzfeldt-Jakob disease. and kuru plaque amyloid in

2 Strittmatter WJ, Saunders AM, Schmechel D, et al. Apolipoprotein $\mathrm{E}$ : high avidity binding to beta-amyloid and increased frequency of type 4 allele in late-onset familia Alzheimer's disease. Proc Natl Acad Sci USA 1993;90: 1977-81.

3 Corder EH, Saunders AM, Strittmatter WJ, et al. Gene dose of apolipoprotein $\mathrm{E}$ type 4 allele and the risk of Alzheimer's disease in late onset families. Science 1993; 261:921-3.

4 Borgaonkar DS, Schmidt LC, Martin SE, et al. Linkage of late-onset Alzheimer's disease with apolipoprotein E type 4 on chromosome 19 confirmed by family studies. Lancet 1993;342:625.

5 Poirier J, Davignon J, Bouthillier D, Kogan S, Bertrand P, Gauthier S. Apolipoprotein E polymorphism and Alzheimer's disease Lancet 1993:342:697-9.

6 Noguchi S, Murakami K, Yamada N. Apolipoprotein E genotype and Alzheimer's disease. Lancet 1993;342:737.

genotype and Alzheimer's disease. Lancet 1993;342:737. Apolipoprotein E genotype and Alzheimer's disease. Lancet Apolipoprotein 8 Mayeaux R, Stern Y, Ottman R, et al. Apolipoprotein E $\varepsilon 4$ allele as a risk

Scott J. Apolipoprotein E and Alzheimer's disease. Lancet 1993;342:696-7.

10 Wisniewski T, Frangioni B. Apolipoprotein E: a pathologica chaperone protein in patients with cerebral and systematic amyloid. Neurosci Lett 1992;135:235-8.

11 Saunders AM, Strittmatter WJ, Schmechel D, et al. Association of apolipoprotein $\mathrm{E}$ allele $\varepsilon 4$ with late onset familial and sporadic Alzheimer's disease. Neurology 1993, 43:1467-72.

12 Alzheimer's Disease Collaborative Group. Apolipoprotein E genotype and Alzheimer's disease. Lancet 1993;342:737-8.

3 Van Broeckhoven C, Backhovens $\mathrm{H}$, Cruts M, et al. APOE gentype does not modulate age of onset in families with genotype does not modulate age of onset in families with chromosome 14

14 Chartier Harlin MC, Parfitt M, Legrain S, et al. Apolipoprotein $\mathrm{E}, \varepsilon 4$ allele, as a major risk factor for sporadic lipoprotein E, $\varepsilon 4$ allele, as a major risk factor for sporadic early and late onset forms of Alzheimer's disease: analysis of the $19 \mathrm{q} 13.2$

15 Okuizumi $\mathrm{K}$, Onedera $\mathrm{O}$, Tanaka $\mathrm{H}$, et al. ApoE-E4 and early onset Alzheimer's. Nature Genet 1994;7:10-11.

6 Van Duijn CM, de Knijff P, Cruts M, et al. Apolipoprotein $\mathrm{E} \varepsilon 4$ allele in a population based study of early onse Alzheimer's disease. Nature Genet 1994;7:74-8.

17 McKhann LE, Drachman D, Folstein M, et al. Report of the NINCDS-ADRDA work group under the auspices of Department of Health and Human Services Task Force of Alzheimer's disease. Neurology 1984;34:939-44

18 Jones CT, Morris S, Moffoot A, et al. Screening Alzheimer's disease patients for mutations in the amyloid precursor protein gene. Mol Cell Probes 1993;7:161-5.

19 Cumming AM, Robertson FW. Polymorphism at the Apolipoprotein $\mathrm{E}$ locus in relation to risk of coronary disease. Clin Genet 1984;25:310-13.

20 St Clair D, Norrman J, Perry RH, et al. Apolipoprotein E $\varepsilon 4$ allele frequency in Lewybody dementia, Alzheimer's $\varepsilon 4$ allele frequency in Lewybody dementia, Alzheimer's dis-6.

21 Wenham PR, Price EH, Blundell A. Apolipoprotein E genotyping by one stage PCR. Lancet 1991;337:1158-9. 